\title{
Influence of Gender and Environment on the Occurrence of Chronic Obstructive Pulmonary Disease: Cross-Sectional Study
}

\author{
Fiston Dikamba Fiondo ${ }^{1}$, Benjamin Longo Mbenza $^{2,3}$, David Kizungu Milinganya ${ }^{1}$, \\ Alex Tukadila Kabangi ${ }^{3}$, Michel Lelo Tshikwela ${ }^{1}$, Jean Mukaya Tshibola ${ }^{1}$, \\ Aliocha Nkodila Natuhoyila, ${ }^{3}$, \\ ${ }^{1}$ Department of Radiology, University of Kinshasa, Kinshasa, Democratic Republic of Congo \\ ${ }^{2}$ Department of Internal Medicine, University of Kinshasa, Kinshasa, Democratic Republic of Congo \\ ${ }^{3}$ Department of Public Health, Lomo University Reseach, Kinshasa, Democratic Republic of Congo
}

Email address:

nkodilaaliocha@gmail.com (A. N. Natuhoyila)

${ }^{*}$ Corresponding author

\section{To cite this article:}

Fiston Dikamba Fiondo, Benjamin Longo Mbenza, David Kizungu Milinganya, Alex Tukadila Kabangi, Michel Lelo Tshikwela, Jean Mukaya Tshibola, Aliocha Nkodila Natuhoyila. Influence of Gender and Environment on the Occurrence of Chronic Obstructive Pulmonary Disease: Cross-Sectional Study. Cardiology and Cardiovascular Research. Vol. 4, No. 4, 2020, pp. 210-214. doi: 10.11648/j.ccr.20200404.17

Received: August 2, 2020; Accepted: October 12, 2020; Published: November 24, 2020

\begin{abstract}
Background and Objective: Chronic obstructive pulmonary disease (COPD) is predicted to be the third leading cause of death worldwide by 2020. Its diagnosis remains a challenge in developing countries such as DRC, with the use of Gold standard, spirometry, limited. Chest imaging plays an important role in orientation. The absence of local radiological data from COPD had therefore motivated this study. The aim of this study is to establish a relationship between gender, environment and COPD. Materials and Methods: Retrospective and analytical study of clinical and thoracic imaging data (radiography and CT scan), collected from the records of 120 COPD subjects followed in three Kinshasa medical trainings between January 2014 and June 2017. Fisher's test compared the results obtained. The combination of imaging data and clinical phenotype through Pearson chi-square testing, logistic regression and odds-ratio (OR). The service threshold was set at 0.05. Results: the study population (average age of $64.52 \pm 6.82$ years) was predominantly male $(78.3 \% \mathrm{n}=94)$. Results: the study population (average age of $64.52 \pm 6.82$ years) was predominantly male $(78.3 \% \mathrm{n}=94)$. The proportions of sputum were more common in men than in women, the difference being statistically significant. Indeed, the male sex confers a triple risk $(\mathrm{OR}=3.1$; IC 95\% 1.2-8; $\mathrm{P}=0.015)$. Women were more exposed to domestic and/or occupational pollution $(65.4 \% \mathrm{n}=17$; than men were $(26.6 \% \mathrm{n}=25)$. Indeed, the male sex conferred a risk of exposure to domestic pollution and/or occupational pollution multiplied by 14 times $(\mathrm{OR}=14.3$; IC 95\%; 2-100; $\mathrm{P}=0.001)$ and allergy conferred a risk of exposure to domestic pollution by 17 times $(\mathrm{OR}=17.1$; IC95\%: 2.1-137, $\mathrm{p}=0.007)$. Conclusion: This study showed the male sex and allergy is conferred a high risk of the domestic pollution or occupation pollution.
\end{abstract}

Keywords: COPD, Environment, Sex, Radiological Profile, Kinshasa

\section{Introduction}

Chronic obstructive pulmonary disease (COPD) has been a disease that has been on the rise in the world for 20 years, with more than 44 million patients worldwide, or $4-10 \%$ of the adult population $[1,2]$.

This disease is caused by chronic inhalation of harmful particles and / or gases. Indeed, several studies carried out in the West have made it possible to establish the harmfulness of smoking and atmospheric pollution in the occurrence of this disease in well-off countries. Likewise domestic pollution, biomass and fuel particles have been implicated in 
the genesis of COPD in developing countries [3, 4]. Several comorbidities are associated with it, reported in the literature, in particular cardiovascular diseases $[1,5]$.

This disease is the fifth leading cause of death in the world after heart attacks, strokes, community respiratory infections and tuberculosis $[1,8]$. COPD mortality increased to $47 \%$ in the United States (USA) between 1979 and 1993 [6]. The forecasts of the World Health Organization (WHO) are much more alarming for the year 2020 when the disease will become the third cause of death attributable to smoking, especially among women $[6,7]$.

The DR Congo, our country is not spared by this pandemic of the century and some studies in the middle have already shown the existence of some risk factors for COPD, as well as the harmful role of smoking at $17.5 \%$ and $25 \%$ exposure to industrial pollutants in the city of Kinshasa [8,9]. Chest imaging plays an important role in the referral diagnosis, but data is lacking. The aim of this study is to establish a relationship between gender, environment and COPD.

\section{Materials and Methods}

\subsection{Material}

\subsubsection{Type and Study Period}

It is a cross section and analytical study, based on the exploitation of the various records of the pneumology services, dated January 01, 2014 to June 01, 2017.

\subsubsection{Study Framework}

This is a multi-center study, conducted simultaneously at the Kinshasa University Clinics (CUK), the Kinshasa General Reference Hospital (HGRK), the BIAMBA Marie MUTOMBO Hospital (HBMM); all residents of Kinshasa. The choice of these institutions was justified by their respective capacities to handle COPD cases.

\subsubsection{Different Conventional X-ray Machines Used}

Were used the Hitachi model ZU-L3TY (year 2011), Siemens iconos R 100 (year 2006) and Allengers (year 2008) respectively at CUK, HMBM and HGRK.

The acquisition settings were 60 to $75 \mathrm{KV} / 22 \mathrm{mAs}$ for the front RTS shot and 90 to $110 \mathrm{KV} / 28 \mathrm{mAs}$ for the profile shot. Automatic development with cassette decoding by an AGFA laser CXR $35 \AA$ preceded the archiving of images on $\mathrm{CD}$ with embedded reading software (I-viewer $\left.{ }^{\circledR}\right)$.

\subsection{Methods}

\subsubsection{Variable Methods of Interest}

Sociodemographic Variables (Sex, Age), Epidemiological data (Concept of tobacco use, exposure to domestic and industrial pollutants, cormobidity), Clinical data (Cough, dyspnea, sputum) and paraclinical data were collected.

\subsubsection{Statistical Analysis}

The entry of compac-branded computer data and statistical calculations were made using EPI INFO version 7.0 and IBM SPSS 23.0 software on Windows 10. The data were represented by proportions (\%) or absolute frequencies for quantitative variables and averages; deviation-types with their extremes for qualitative variables. The Pearson chisquare test was used to compare proportions, and the student test was used to compare average ages.

The univariate risk was assessed with a 95\% confidence interval by odds-ratio or odds-ratio using the contingency table and the Manteel Haenszel test with the Yates correction if necessary.

The value of $\mathrm{p}<0.05$ was considered a threshold of statistical significance.

\section{Results}

\subsection{Health Structures and Patient}

Care Among all patients $(n=120), 63.3 \%(n=76), 23.3 \%$ $(\mathrm{n}=28)$ and $16.3 \%(\mathrm{n}=16)$ were treated respectively at CUK, HGHK and HBMM.

\subsection{Sex and Epidemiology-Clinical Variable}

The distribution of occupational exposure proportions, allergy, comorbidity and type of comorbidities were similar $(\mathrm{P}>0.05)$ between men and women. On the other hand, there was a significant relationship $(\mathrm{P}<0.05)$ between health facilities, cigarette smoking, exposure to domestic pollution and sex as described in Table 1. There was still a significant overrepresentation $(\mathrm{P}=0.042)$ of male patients than of female patients between different health facilities and in each health structure. Males had a risk factor dominated by smoking, while women smoked less than men, with a statistically significant difference. Unfortunately, women were more exposed to domestic pollution than men, the difference being statistically very significant.

Table 1. Epidemiological and environmental characteristics of COPD by males and females.

\begin{tabular}{llll}
\hline Variables of interest & All \% (n) & Men \% (n) & Women \% (n) \\
\hline Hospitals & & & P value \\
CUK & $63.3(76)$ & $84.2(64)$ & $15.8(12)$ \\
HGRK & $23.3(28)$ & $75(21)$ & $25(7)$ \\
HBMM & $16.3(16)$ & $56.3(9)$ & $43.7(7)$ \\
Exposure-risk & & & \\
Active cigarette smoking & $32.5(39)$ & $40.4(38)$ & $3.8(1)$ \\
Domestic pollution smoke & $30.8(37)$ & $21.3(20)$ & $65.4(17)$ \\
Occupational pollution smoke & $5.8(7)$ & $5.3(5)$ & $7.7(2)$ \\
Ageing & & & \\
$<40$ years & $7.5(9)$ & 0.001 & 0.648 \\
15-59 years & $25(30)$ & $26.6(25)$ & 0 \\
\hline
\end{tabular}




\begin{tabular}{lllll}
\hline Variables of interest & All \% (n) & Men \% (n) & Women \% (n) & P value \\
\hline$\geq 60$ years & $75(90)$ & $73.4(69)$ & $100(26)$ & \\
\hline
\end{tabular}

\subsection{Sex and Chest Scanner Given}

The proportions of pulmonary artery dilation, panlobular emphysema; paraseptal emphysema, and bubble emphysema were comparable $(\mathrm{P}>0.05)$ between men and women as stipulated in Table 2.
All the time women tended to present panlobular emphysema more than men did. Men tended to exhibit bubble emphysema, paraseptal emphysema and dilation of the pulmonary artery no longer did women.

Table 2. Variation in the levels of centroobular emphysema, lobular pan-panemly emphysema with the predominant airways, Mixed achieving predominant emphysematic impairment between the interaction group, between sex and aging.

\begin{tabular}{|c|c|c|c|c|}
\hline Variables of interest & Men with ageing \% (n) & Men to the State young-adult \% (n) & Women with ageing \% (n) & Value P \\
\hline Centrolobular Emphysema & $44.4(8)$ & $100(8)$ & $0(0)$ & $<0.0001$ \\
\hline Lobular pan-lobular emphysema & $44.4(8)$ & $0(0)$ & $66.7(4)$ & 0.010 \\
\hline Predominant emphysematous reach & $72.2(13)$ & $12.5(1)$ & $33.3(2)$ & 0.013 \\
\hline Mixed Reach & $44.4(8)$ & $0(0)$ & $0(0)$ & 0.016 \\
\hline
\end{tabular}

\subsection{Sex and Clinical Manifestation of COPD}

The proportions of sputum were more common in men than in women, the difference being statistically significant. Indeed, the male sex confers a triple risk $(\mathrm{OR}=3.1$; IC 95\% $1.2-8 ; \mathrm{P}=0.015)$. Women were more exposed to domestic and/or occupational pollution $(65.4 \% \mathrm{n}=17$; than men were $(26.6 \% \mathrm{n}=25)$. Indeed, the male sex conferred a risk of exposure to domestic pollution and/or occupational pollution multiplied by 14 times (OR=14.3; IC 95\%; 2-100; $\mathrm{P}=0.001)$ and allergy conferred a risk of exposure to domestic pollution by 17 times $(\mathrm{OR}=17.1$; IC95\%: 2.1-137, $\mathrm{p}=0.007)$.

Table 3. Independent determinants of the presence of expiratory trapping in the study population.

\begin{tabular}{llccc}
\hline Independent Variables & B & ES & Wald & aOR (IC95\%) \\
\hline $\begin{array}{l}\text { Sex } \\
\text { Women }\end{array}$ & 2.680 & 0.986 & 7.389 & Value p \\
$\begin{array}{l}\text { Men } \\
\text { Allergy }\end{array}$ & & & $14.3(2-100)$ & 1 \\
Yes & 2.839 & 1.061 & 7.158 & $17.1(2.1-137)$ \\
No & & & & 0.001 \\
\hline
\end{tabular}

\section{Discussion}

This study involved a total of 120 patients with COPD with uneven distribution. The majority of copd patients were treated in the Department of Internal Medicine at university clinics compared to other COPD patients treated at HGRK and HBMM.

Indeed, the CUK has established a tertiary health level to train physicians specializing in radiodiagnosis and medical imaging. In contrast, the proportions of COPD patients were similar between HGRK and secondary health HBMM.

Approximately $40 \%$ of COPD patients were exposed to environmental pollution, $84 \%$ of whom were domestic pollution- compared to $16 \%$ occupational pollution. The socio-political and economic crisis in the DRC without access to electricity exposes the population of the city of Kinshasa to a high risk of COPD $[10,11]$. In addition, the frequency of $5.8 \%$ of occupational pollution in this study was 5 times lower than that of $31.1 \%$ in the US [12].

The city of Kinshasa is today characterized by the smoke of plastics, firewood, the emanation of gas from factories and used vehicles. Worse still, the dust raised by the wind and also that of unpaved roads. The extent of exposure to smoke exhaled by relatives, friends, co-workers and other cigarette or cigar smokers was not specified in this study. Exposure to smoking and other particles induce COPD and other respiratory diseases [13].

The clinical picture of COPD described in this study was similar to that regularly reported in the Gold literature [14]. Indeed, dyspnea and chronic cough were reported in $100 \%$ of patients with COPD. These results corroborate the study of Yaccouba $\mathrm{T}$ et al., in Mali which showed that dyspnea had a frequency of $100 \%$ and cough at $63 \%$ in patients with COPD [15]. On the other hand, expectorations of patients with COPD were less common than dyspnea and chronic cough $95 \%$ of patients with COPD in this study. This disparity could be explained by the influence of seasonality and bacterial exacerbation $[16,17]$.

Characteristic of COPD according to the Literature Gold [14] was not included in our research protocol.

This study highlighted the coexistence of cardiovascular pathology, diabetes mellitus, interstitial lung disease as reported in the literature of Gold [15] and a study in Kinshasa conducted by Tshiasuma [9]. The multimorbirity concept defined by the World Health Organization (WHO) as the concomitant presence of at least 2 chronic medical conditions in the same individual [30], requires a more generalized approach to the patient through 
personalized (individualized) medicine [18].

Multimorbidity in COPD in poor patients, aged, tabagic, underdiagnosed and under-treated in Kinshasa hospital settings will be more vulnerable to hospitalization and mortality as reported in the literature $[19,20]$

During the progression of COPD [18], spirometry and volume flow curve defined the severity of obstructive ventilatory disorder by VEMS/CVF 0.7 and $80 \%$ in this study.

As the classification of Gold by exacerbation [14] is not universally accepted, spirometry remains the most invasive, sensitive and objective tool for measuring obstructive ventilatory dysfunction despite its low specificity [21].

This study characterized certain radiographic aspect of the face and profile chest in patients with COPD. Pulmonary distension was the dominant sign on head chest $\mathrm{x}$-rays during this study in $80 \%$ of cases. Bronchial parietal rail thickening came second in $60.8 \%$, followed by HATP in $52 \%$, emphysema bubble in $46.7 \%$ of cases. These results are similar to those of Muller NL et al. in Canada [22] who noted the prevalence of pulmonary distension (pulmonary hyperinflation) and pulmonary emphysema in COPD patients.

This study shows that bronchial parietal thickening, centro-lobular emphysema and predominant emphysematous impairment is the computational expression of COPD in $68.75,50 \%$ and $50 \%$ of cases, respectively. These results are similar to those of Fernandes L et al. in India [10] who had shown that dominant emphysematic impairment was common in the COPD patient. Bruno $\mathrm{H}$ et al. in Brazil [10] also stated that dominant emphysematic impairment was most common in patients with COPD.

This study also characterized COPD phenotyping during aging through chest radiographic abnormalities and CT scans of the chest. In this study, the expiratory trapping defined on chest x-ray was primarily related to the female sex, while the literature shows that male sex are more prone to cigarette smoking and trapping in the developed country [15, 22].

In conclusion, this clinical-radiographic study of COPD in the urban environment of Kinshasa has almost come to the same conclusion as that reported in the literature: male volunteer predominance in the 6th decade of life; The harmful role of smoking as a predisposing risk factor; the relatively frequent association of COPD with cardiovascular disease; the existence of COPD phenomenon characterized by mixed impairments (coexistence of predominant emphysematic impairment and predominant airway impairment), bubble emphysema, lobular pan-pan emphysema, and centrolubular emphysema according to aging and male sex.

However, despite the above, there are many signs to more easily recognize on simple chest $\mathrm{x}$-ray beyond stage I, including pulmonary distension, bronchial parietal rail thickening and the presence of emphysema bubbles; this is even in the absence of CT and spirometry.

\section{Conclusion}

This clinical-radiographic study of COPD in the urban environment of Kinshasa has almost come to the same conclusion as that reported in the literature: male volunteer predominance in the 6th decade of life; The harmful role of male sex et allergy as a predisposing risk factor for the domestic pollution.

\section{Author's Contributions}

FDF, BLM, ANN, DKM and HAT designed and analyzed the statistical data for the study. MLT and JMT supervised the study. All authors have read and approved the final and revised version of the manuscript.

\section{Conflict of Interest}

The authors declare no conflict of interest.

\section{Acknowledgements}

We thank all who participated in the study.

\section{References}

[1] Lopez AD, Shibuya K, Rao C et al. Chronic obstructive pulmonary disease: current burden and future projections. Eur Respir J 2006; 27: 397-412.

[2] Murray CJ, Lopez AD. Alternative projections of mortality and disability by cause 1990-2020: Global burden of disease study. Lancet 1997; 349: 1498-1504.

[3] Pauwels RA, Buist AS, Jenkins CR, et al., Global strategy for the diagnosis, management and prevention of chronic obstructive pulmonary disease: National Heart, Lung, and Blood Institute and World Health Organization Global Initiative for Chronic Obstructive Lung Disease (GOLD): executive summary. Respir Care 2013; 176: 532-5.

[4] Khated Ait, Enarson D, Bousquet J. les maladies respiratoires chroniques dans les pays en développement: charges des morbidités et stratégies de prévention et de prise en charge, Bulletin de l'OMS recueil d'articles No 6, 2002; 115-20.

[5] Burgel P-R. Comorbidité dans la BPCO: causes ou conséquences. Rév Mal resp 2010; 25: 12-5.

[6] Charie-H Marquette. Pneumologie. Collège des enseignants de pneumologie, S Edition. Paris 2011, 200-50.

[7] Aubier M, Crestani B, Michel F. Traité de pneumologie $2^{\text {ème }}$ éd, Paris, Flammarion 2009; 230-50.

[8] Kapinga S. Santé respiratoire et environnement dans la ville de Kinshasa. Mémoire de spécialisation, Unikin 2012; 35-40.

[9] Tshiasuma M. La broncho-pneumopathie chronique obstructive: Profil épidemio-clinique et principales comorbidités dans quelques hôpitaux de Kinshasa, Mémoire de fin de spécialisation. Unikin 2013, 41-55.

[10] Ballon C. E, Ione SW et al associated loss of fat-free mass and bone mineral density in chronic obstructive pulmonary disease. Am j respire crit care med 2004; 170: 1286-93. 
[11] Anthonisen NR et al. smoking and lung function of health study participants after 11 years. Am $\mathrm{j}$ respir crit care med 2002; 166: 675-79.

[12] Hnizdo E, et al. Association between chronic obstructive pulmonary disease and employment by instruction and occupation in the US population: a study of data from the third national health and nutrition examination survey. Am $\mathrm{j}$ Epidemiol 2002; 156 (8): 738-46.

[13] Yin P. Passive smoking exposure and risk of COPD among adults in china: the guangzhou biobank cohort study lancet 2007; 370 (9589): 751-7.

[14] Alvar G. Global strategy for the diagnosis, Management, and prevention of chronic obstructive pulmonary disease 2017. Web site www.goldcopol.org.1-122.

[15] Yacouba T. Broncho-pneumopathie chronique obstructive. Journée académique du conseil de l'ordre des médecins du mali 2017, 20-30.

[16] Eisner MD. Official american thoracic society public policy statement: Novel risk factors and the global burden of chronic obstructive pulmonary disease. Am j respir crit care Med 2010; 182 (5): 693-718.

[17] Salvi S et al. Chronic obstructive pulmonary disease in nonsmokers. Lancet 2009; 374 (9691): 733-43.

[18] Sophie. multimorbidité. rumed suisse 2016; volume 12. 91721.

[19] Scheen A. Médecine personnalisée: tout bénéfice pour le patient mais nouveau challenge pour la relation médecinmalade. Revue médicale de liège 2015; volume 70: 5-6.

[20] Huiart L. Cardiovascular morbidity and mortality in COPD chest. oct 2005; 128 (4): 2640-6.

[21] Curkendall SM. Cardiovascular disease in patients with chronic obstructive pulmonary disease, saskatchewan canada cardiovascular disease in COPD patients. Ann Epidemiol janv 2006; 16 (1): 63-70.

[22] Miller MR, et al. Standardisation of spirometry. Eur Respir J 2005; 26 (2): 319-38. 